\title{
Neurilemmoma of the anterior ethmoidal nerve encroaching upon the nasolacrimal duct
}

\author{
Martin L Leib, Emil W Chynn, Peter Michalos, Hermann D Schubert, Ethan J Leib
}

\section{Orbit and Plastics \\ Service, The Edward S \\ Harkness Eye Institute, \\ Columbia-Presbyterian \\ Medical Center, New \\ York \\ M L Leib \\ P Michalos}

\section{The Algernon B Reese} Laboratory of Ophthalmic Pathology, The Edward S Harkness Eye Institute, New York H D Schubert

The College of Physicians and Surgeons, Columbia University, New York

$M$ L Leib

E W Chynn

H D Schubert

The Ramaz School, New

York

E J Leib

Correspondence to:

Martin L Leib, MD, Director, Orbit and Ophthalmic Plastic

Surgery, The Edward S

Harkness Eye Institute,

Columbia-Presbyterian

Medical Center, 635 West

165th Street, Suite No 230

New York, New York 10032,

USA.

Accepted for publication

22 June 1992

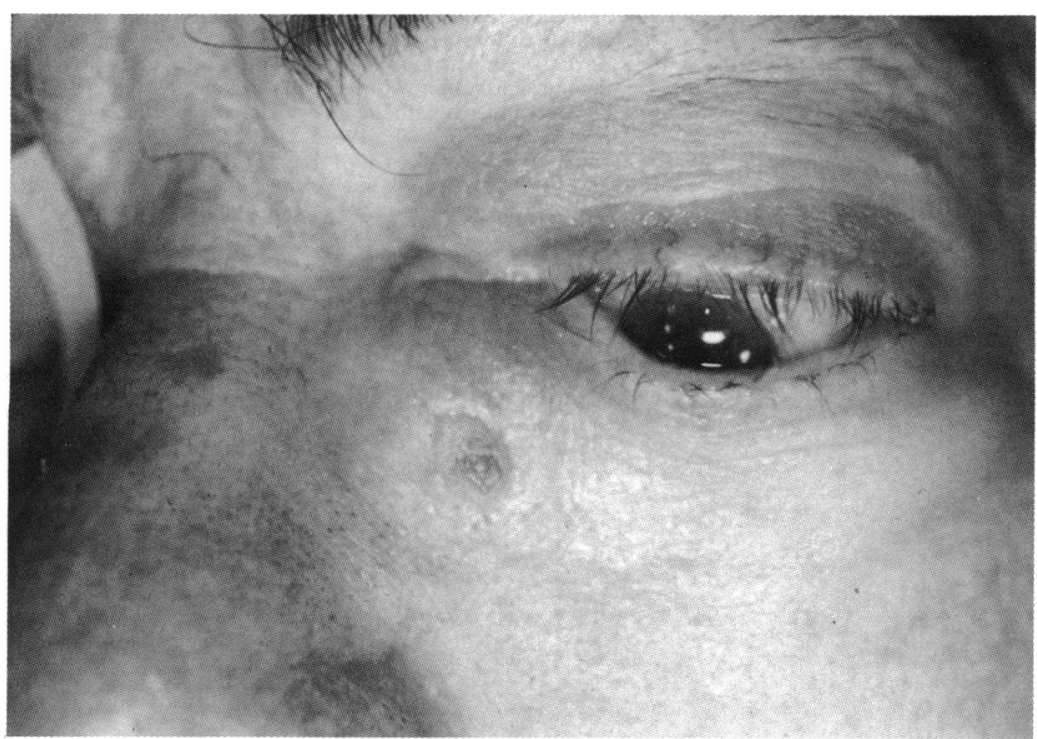

Figure 1 Preoperative photograph demonstrates left periorbital mass.

\begin{abstract}
The clinical, light microscopic, ultrastructural, and immunohistologic findings of a neurilemmoma encroaching upon the nasolacrimal duct are presented. This is the first reported case of this rare tumour of the nasolacrimal duct where the diagnosis has been confirmed by electron microscopy and immunohistochemical techniques.
\end{abstract}

(BrF Ophthalmol 1992; 76: 750-752)

\section{Clinical history}

A 72-year-old white diabetic female complained of chronic epiphora of the left eye of 1 year's duration and a growing mass nasal to the medial canthus of the left anterior orbit of 8 years' duration (Fig 1). The patient denied any history of diplopia proptosis, orbital pain, trauma, sinusitis, or inflammation. Personal and family history were negative for café au lait spots and neurofibromas. Past medical history was notable for insulin-dependent diabetes mellitus of 30 years' duration, for which the patient was on a regimen of insulin and isophane insulin injections. Surgical history was notable for cataract extraction and intraocular lens implantation in the right eye 2 years previously and laser photocoagulation for diabetic retinopathy in the right eye.

On examination the best corrected visual acuity was $20 / 80 \mathrm{OD}, 20 / 60 \mathrm{OS}$. On palpation a large, firm, movable, ovoid mass was felt, with no expression of fluid on compression of the nasolacrimal duct. Irrigation revealed a partial obstruction to flow beyond the common canaliculus. Dacryocystography revealed the nasolacrimal duct to be displaced anteriorly and flattened by a round, well-circumscribed mass located directly behind the sac (Fig 2). The mass partially obstructed the nasolacrimal duct as evidenced by a limited amount of contrast medium entering the nose and pharynx, with splaying of contrast medium over the nasolacrimal mass on the 25 minute film.

Surgical exploration under general anaesthesia via an incision over the anterior lacrimal crest revealed a solid, well-circumscribed, encapsulated lesion completely filling the nasolacrimal duct (Fig 3).

Intraoperative frozen section showed a spindle cell tumour. The lesion appeared to arise from a nasal branch of the anterior ethmoidal or infraorbital nerve supplying the nasolacrimal duct. The tumour was removed in its entirety; it measured approximately $1.5 \times 2.5 \mathrm{~cm}$. Probing demonstrated a stenotic upper and a partially obstructed lower lacrimal system. Silastic intubation was performed and the residual dome of the sac was used to complete a modified Illif dacryocystorhinostomy. The patient tolerated the procedure well and had an uneventful recovery, with complete resolution of epiphora.

\section{Pathology}

Histological examination revealed a spindle cell neoplasm, arranged in bundles and fascicles with foci of increased cellularity, suggestive of palisading (Fig 4). Mucoid degeneration, microcyst formation, and calcification were absent. Tumour cell nuclei were 'wavy' and in some areas 'tear drop' shaped with rare mitoses. Blood vessel walls appeared thickened due to hyalinisation. The histopathological differential diagnosis included neurilemmoma, leiomyoma, and neurofibroma.

Electron microscopy (EM) demonstrated spindle cells with intracellular granules, possible basement membrane formation, and minimal rough endoplasmic reticulum (Fig 5). Immunoperoxidase staining showed tumour cell expression of S-100 protein and vimentin (Fig 6). Staining for desmin, muscle actin, smooth muscle actin, and neuron-specific enolase were negative. Given the histology, EM features, and characteristic immunohistochemical staining, the diagnosis of neurilemmoma was made.

\section{Discussion}

Neurilemmoma is a benign nerve sheath tumour of Schwann cell origin which is rare in the orbit. In a review of the literature between 1935 and 1963 by Schatz, 'only 25 benign neurilemmomas and 14 malignant neurilemmomas were reported out of 2196 case of unilateral exophthalmos or 


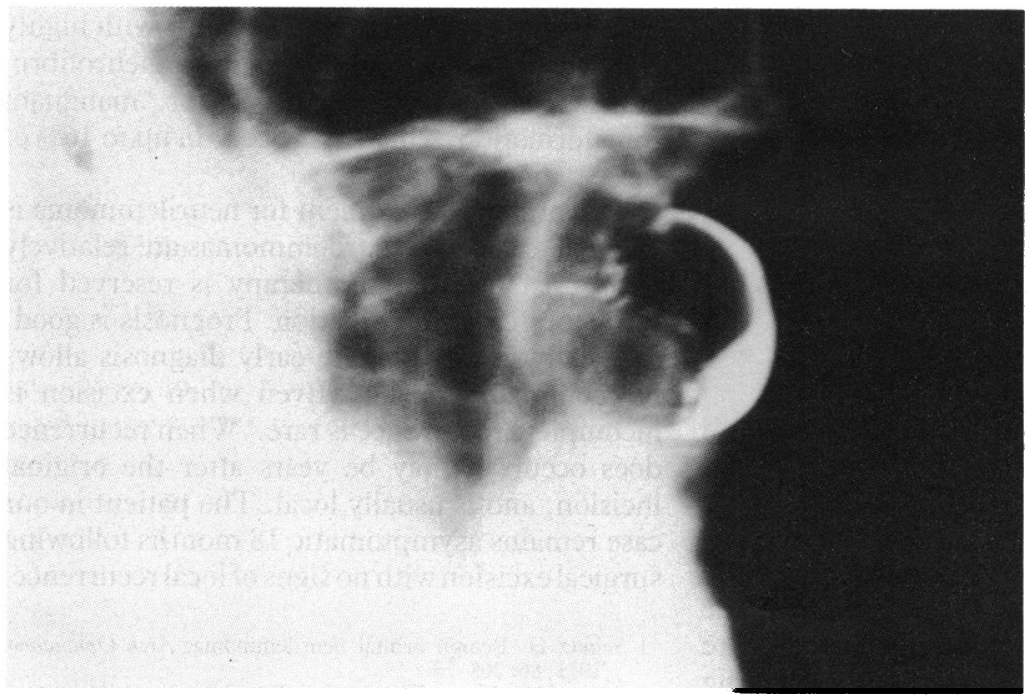

Figure 2 Dacryocystogram reveals anterior displacement, flattening, and partial obstruction of nasolacrimal duct by rounded posterior mass.

orbital tumours. Neurilemmoma accounts for approximately $1 \%$ of orbital neoplasias. ${ }^{1-4}$ It is known to be a tumour of adulthood, though the age of onset may range from 20 to 70 years. No sex predilection has been shown.

Neurilemmoma usually arises from branches of the supraorbital or supratrochlear nerves; less commonly it may arise from the infraorbital, ciliary, oculomotor, trochlear, or abducens nerves. ${ }^{5}$ Non-orbital cases have been reported rarely arising from the lid, conjunctiva, limbus, sclera, ${ }^{67}$ ciliary body, ${ }^{8}$ and choroid. ${ }^{9}$

Only one other case of neurilemmoma rising from the area of the nasolacrimal duct has been reported. ${ }^{10}$ In that case, however, the diagnosis was based solely on light microscopy without immunohistochemical staining or EM confirmation and no reference was made as to the probable nerve of origin. In our case, diagnosis was based on the characteristic gross, light microscopic, EM, and immunohistochemical appearance of the tumour, which intraoperative dissection showed as arising from a nasal branch of the anterior ethmoidal or infraorbital nerves supplying the nasolacrimal duct. In 17 cases of neurilemmoma, reviewed by Dervin et al, none presented with epiphora though $41 \%$ were located in the lower nasal quadrant. ${ }^{11}$

As in our case, neurilemmomas are usually solitary, well-encapsulated tumours of round, ovoid, or fusiform shape. ${ }^{13510}$ Histologically, neurilemmomas are composed of spindle shaped cells which may be arranged in either an Antoni

Figure 3 Intraoperative photograph of solid, wellcircumscribed, encapsulated lesion completely filling nasolacrimal duct.

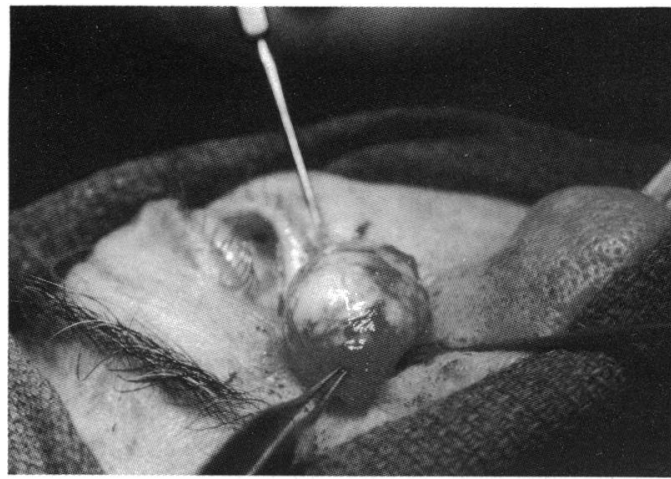

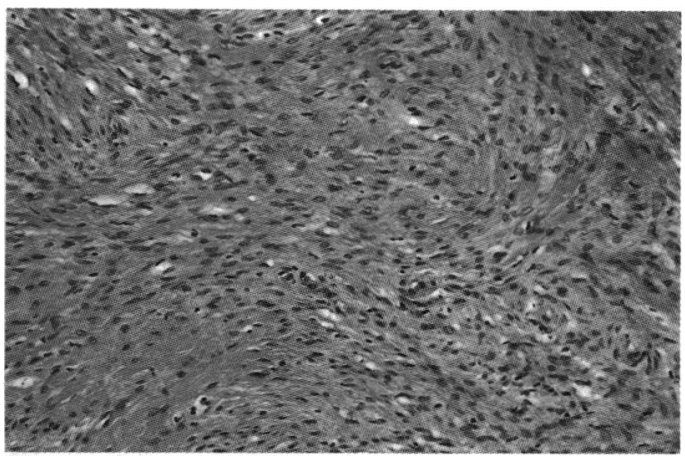

Figure 4 Characteristic palisading (Antoni A) pattern of spindle cell neoplasm, with cells arranged in bundles and fascicles with foci of increased cellularity (haematoxylin and eosin, $\times 55)$.

A (palisading) or Antoni B (mucoid degeneration) pattern, the former being the more common. The Antoni B pattern may be associated with central areas of central haemorrhage or calcification within the myxoid stroma.

The EM appearance of neurilemmoma is thought to be characteristic. Spindle cells with intracellular granules, basement membrane formation, and minimal rough endoplasmic reticulum are the rule. Extracellular collagen with foci of long-spacing collagen ('Luse bodies') may also be present..$^{81213}$

Immunohistochemical stains are useful to differentiate neurilemmomas from tumours of similar light microscopic appearance. Neurilemmomas characteristically express S-100 protein and vimentin. ${ }^{14}$ In contrast to leiomyomas, neurilemmomas stain negative for desmin, muscle actin, and smooth muscle actin.

The differential diagnosis between neurilemmoma and neurofibroma is more difficult to make using histochemical techniques. While neurofibromas stain positive with Alcian blue, neurilemmomas may stain either Alcian blue positive or negative, depending on whether they are of the Antoni A or B types, respectively. More useful in the case of Antoni A neurilemmomas is their gross and light microscopic appearance, which is typically well-encapsulated and arranged in an orderly palisading fashion, unlike neurofibromas.

In our case, the diagnosis of leiomyoma was

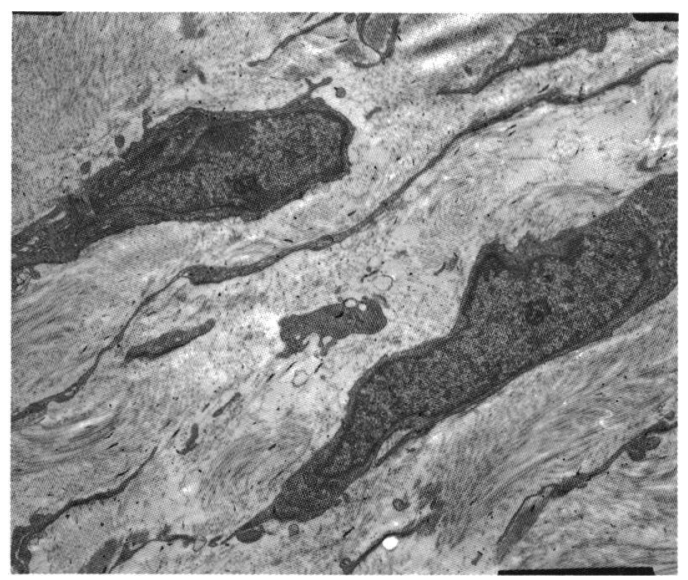

Figure 5 Electron photomicrograph of spindle cells with intracellular granules, possible basement membrane formation, and minimal rough endoplasmic reticulum. 
Figure 6

Immunoperoxidase staining reveals tumour expression of $S-100$ protein and vimentin.

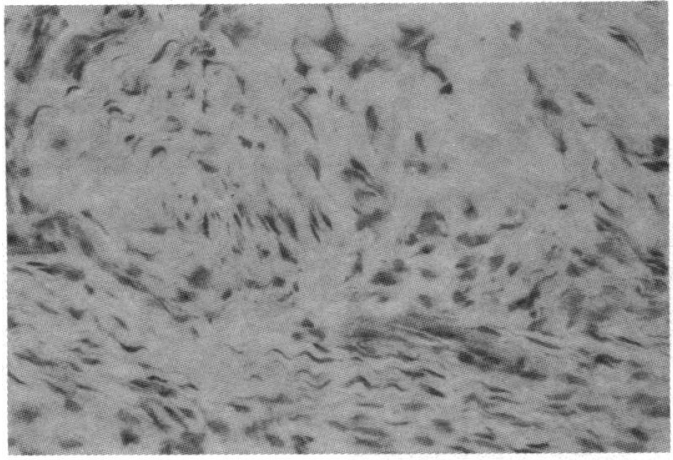

unlikely given the negative staining for muscle actin and smooth muscle actin, as well as the 'wavy' and 'tear drop' shaped nuclei with rare mitoses. Though the immunoperoxidase staining pattern was consistent with either neurofibroma or neurilemmoma, the well encapsulated nature of the lesion and palisading histology made for the diagnosis of neurilemmoma.

The clinical presentation and features of neurilemmoma are variable. Neurilemmomas are usually unilateral, slow-growing, and noninvasive. ${ }^{1510}$ Orbital neurilemmomas often present with exophthalmos, decreased visual acuity, pain, or diplopia. Findings may include ophthalmoplegia, pupillary involvement, and fundus changes, such as disc oedema or optic atrophy. ${ }^{2}$ Extraorbital neurilemmoma may have similar signs and symptoms depending upon anatomical involvement. In both our case and the other reported case of neurilemmoma of the nasolacrimal duct, a presenting complaint was painless swelling nasal to the medial canthus of one eye. Our case differed, however, in that epiphora was also prominent.

Neurilemmomas are benign and do not metastasise, though malignant transformation has been known to occur very rarely. Lyons $e t a l$ described three such cases. ${ }^{15}$ Patients with highly cellular tumours or concurrent neurofibromatosis are at greater risk for malignant transformation, which may occur in up to $16 \%$ of these patients.'

The preferred treatment for neurilemmoma is surgical excision. Neurilemmomas are relatively radioresistant, so radiotherapy is reserved for refractory cases or palliation. Prognosis is good, especially in cases where early diagnosis allows for complete excision. Even when excision is incomplete recurrence is rare. ${ }^{8}$ When recurrence does occur, it may be years after the original incision, and is usually local. The patient in our case remains asymptomatic 18 months following surgical excision with no signs of local recurrence.

1 Schatz H. Benign orbital neurilemmoma. Arch Ophthalmol 1971; 86: 268-73.

2 Allman MI, Frayer WC, Hedges TR. Orbital neurilemmoma. Ann Ophthalmol 1977; 9: 1409-13.

3 Bergin DJ, Parmely VP. Orbital neurilemmoma. Arch Ophthalmol 1988; 106: 414-5.

4 Reese AB. Tumors of the eye, 2nd ed. New York: Hoeber, $1963 ; 190-202,534-5$

5 Shields JA. Diagnosis and management of orbital tumors. Philadelphia: Saunders, 1989: 152-7.

6 Quere MA, Richir C, Davenne C. Schwannome limbique evolution maligne. Arch Ophthalmol 1964; 24: 285-90.

7 Szabo G, Cseh E. Sklera-Neurinom der Nahe des Limbus. Ophthalmologica 1943; 106: 14-6.

8 Hufnagel TJ, Sears ML, Shapiro M, Kim JH. Ciliary body neurilemmoma recurring after 15 years. Graefes Arch Clin Exp Ophthalmol 1988; 226: 443-6.

9 Packard RBS, Harry J. Choroidal neurilemmoma: an unusual clinical misdiagnosis. Br f Ophthalmol 1981; 65: 189-91.

10 Sen DK, Mohan H, Chatterjee PK. Neurilemmoma of the nasolacrimal sac. Eye, Ear, Nose, Throat Month 1971; 50 179-80.

11 Dervin JE, Beaconsfield M, Wright JE, Moseley IF. CT findings in orbital tumours of nerve sheath origin. Clin Radiol 1989; 40: 475-9.

12 Rootman J, Goldbeg C, Robertson W. Primary orbital schwannomas. Br f Ophthalmol 1982; 66: 194-204.

13 Russell DS, Rubenstein LJ. Pathology of tumors of the nervous system, 5th ed. Baltimore: Williams \& Wilkins, 1989: 53360.

14 Weiss SW, Langloss JM, Enzinger FM. Value of S-100 protein in the diagnosis of soft tissue tumors with particular in the diagnosis of soft tissue tumors well tumors. Lab reference to benign and
Invest 1983; 49: 299.

15 Lyons CJ, McNab AA, Garner A, Wright JE. Orbital malignant peripheral nerve sheath tumours. $\mathrm{Br} \mathcal{F}$ Ophthal mol 1989; 73: 731-8. 